\title{
Seasonal Trends in Solar Radiation Available at the Earth's Surface and Implication of Future Annual Power Outputs Changes on the Photovoltaic Systems with One and Two Tracking Axes
}

\author{
Bazyomo SD ${ }^{1 *}$, Lawin $\mathrm{EA}^{2}$ and Ouedraogo $\mathrm{A}^{3}$
}

${ }^{1}$ Institute of Mathematics and Physical Sciences, University of Abomey-Calavi, BP 613 Porto-Novo, Benin

${ }^{2}$ Applied Hydrology Laboratory (LHA), University of Abomey-Calavi, BP 4521 Cotonou, Benin

${ }^{3}$ Laboratory of Thermal and Renewable Energies, University of Ouaga, Burkina Faso, Benin

*Corresponding author: Bazyomo SD, Institute of Mathematics and Physical Sciences, University of Abomey-Calavi, BP 613 Porto-Novo, Benin, Tel: +229 64609885 E-mail: sbazyomo@gmail.com

Received date: Mar 02, 2017; Accepted date: Mar 24, 2017; Published date: Mar 30, 2017

Copyright: (C) 2017 Bazyomo SD, et al. This is an open-access article distributed under the terms of the Creative Commons Attribution License, which permits unrestricted use, distribution, and reproduction in any medium, provided the original author and source are credited.

\begin{abstract}
This paper presents analyses of solar seasonal future trend and forecast the annual power output changes of one and two tracking axes photovoltaic system. Using as inputs a set of eight data of the recentest climatic models which involve the solar radiations on all sky and temperatures of West-Africa region, the calculations have been made upon the R environment. The seasonal trend of solar irradiation from 2006-2100 has been analyzed and the outputs power changes from now to the mid-21st century have been determined. Photovoltaic power output is estimated to decrease in all the parts of West-Africa. The results show that for trends from 2006-2100 the maximum is of 0.05 $\mathrm{Wm}^{-2}$ year ${ }^{-1}$ for Gambia and over the period JJA while the changes strongest negative change $0.15 \mathrm{Wm}^{-2}$ year $^{-1}$ and corresponds has season DJF with the Cape Verde. Compared with the periods 2006-2100, all the trends the period 2006-2050 and 2051-2100 are more marked. Compared to the period 2006-2051, the results of the seasonal trends of the period 2051-2100 are marked for certain countries and less for others. Cape Verde always presents the trends weakest of $0.55 \mathrm{Wm}^{-2}$ year ${ }^{-1}$ for the minimum of season JJA. Concerning future changes of power output, largest decreases trends strongest go from $-3 \%$ respectively to $-8 \%$ decade for the systems with axes of traction for the Sierra Leone and the Cote d'Ivoire respectively and from -2 to $-8 \%$ decade for the systems with two axes of tractions for the Sierra Leone and the Cote d'Ivoire.
\end{abstract}

Keywords: West-Africa; Climatic models; Solar radiation; Seasonal trend; Tracking axes; Photovoltaic systems

\section{Introduction}

The mechanization and the substitution of manual labor that have allowed the use of fossil fuels improve the life conditions. In fact all these advances have led to significant individual and collective benefits, such as the reduction or substitution of arduous manual labor, an increase in lifespan and health, improved educational opportunities, increased income, greater individual freedoms (democracy) [1] mainly in northern countries. It is the fundamental input for the production of goods and services, apart from increasing the well-being of the population, through the provision of thermal comfort, light and leisure, among other benefits [2].

However, much of Africa and particularly the West Africa do not yet know all the well-beings mentioned above and aspire. The little existing power generated is produced using fossil fuels, which emit tons of carbon dioxide and other pollution each second [3]. More the use of fossil fuels is particularly concerning given the scenario of dwindling resources, as highlighted by the International Energy Agency [4], which forecasts that fossil fuel reserves will be exhausted in less than a 100 years from now. Worst, the concerns as to the environmental impact of their processing and use, giver rise to a need to reverse current trajectories [1].
A solution to that issue is the use of new source of energy which can provide sustainable development of countries and cause less harm to the environment. People are looking for new source of substitute clean energy.

Due to growing energy deficit in the Economic Community of West African States (ECOWAS) region, many member states have expressed the necessity to mainstream renewable energy into their national policies [5]. The Regional Initiative for Sustainable Energy (IRED) within the West African Economic and Monetary Union (UEMOA) proposes $78 \%$ Renewable Energy penetration by 2030 in the UEMOA electricity system, whereas $62 \%$ will be provided by wind, solar and biomass [5]. Considering only solar energy as a sustainable energy solution it is therefore important not only to quantify the present solar resource but to try and anticipate future behaviors of these all planned centralized electricity system provided by solar.

This research objective is to quantify the present solar resource and to examine the future behaviors of these all planned centralized electricity system provided by solar using mainly the technology of the Photovoltaic (PV) tracking systems. The description of sun-tracking methods can be found at the following references $[3,6,7]$. Compared with flat-plat PV modules the efficiencies of these technologies are more important [8-10]. The main difficulty should come from the high cost of these devices [11] and their maintenance compare with fixed devices.

West Africa is the one of the sunniest areas of the world and solar energy is the only choice that can satisfy the huge and steadily 
Citation: Bazyomo SD, Lawin EA, Ouedraogo A (2017) Seasonal Trends in Solar Radiation Available at the Earth's Surface and Implication of Future Annual Power Outputs Changes on the Photovoltaic Systems with One and Two Tracking Axes. J Climatol Weather Forecasting 5: 201. doi:10.4172/2332-2594.1000201

Page 2 of 9

increasing demand of energy [3]. The need to conduct this study is that the availability and reliability of solar sources are a function of climate conditions, which can vary in light of Global Climate Changes (GCC) related to the emission of greenhouse gases $[11,12]$, caused by changes in the transparency of the atmosphere, not by the Sun itself and air pollution is the important contributor [13]. Indeed, Climate change can affect solar energy resources by changing atmospheric water vapour content, cloudiness and cloud characteristics, which affects atmospheric transmissivity $[14,15]$. This can have effects on electricity generation from PV panels. So, it is therefore important to conduct such study which could highlight all future tendencies of electricity system provided by solar.

Stanton et al. [16] recently present a review of the impacts of climate variability and change on electricity systems in Europe. In this paper they summarize the impacts of climate changes mainly on hydroelectricity and solar electricity for Europe. Concerning the Africa, some authors have studied the impacts of climate changes on horizontal and tilted PV panels. Crook et al. [17] examines global changes in PV and Concentrated Solar Power (CSP) outputs, using two climate change models (HadGEM1 and HadCM3) and the IPCC SRES A1B scenario. They conclude that CSP is more sensitive to climate change than PV and overall solar power from 2010 to 2080 will increase a few percent in Europe and China, stay similar in Algeria and Australia and decrease by a few percent in USA and Saudi Arabia.

Most recent study is from Wild et al. [18]. Wild et al. examine how the latest generation of climate models used for the fifth IPCC report projects potential changes in surface solar radiation over the coming decades, and how this may affect, in combination with the expected greenhouse warming, solar power output from PV systems. They conclude that statistically significant decreases in PV outputs will occur in large parts of the world under the RP C8.5 scenario, but notable exceptions with positive trends in large parts of Europe, southeastern North America and south-eastern China.

Projected changes between 2006 and 2049 under the RCP 8.5 scenario overall are on the order of $1 \% /$ decade for horizontal planes, but may be larger for tilted or tracked planes as well as on shorter (decade) timescales. Using the ECHAM5 global climate to assess the near future changes of PV productivity in Europe and Africa, Gaetani et al. [12] found that reductions in aerosols emissions in the near future result in an increase of global warming, and a significant response in surface solar radiation and associated PV energies productivity. A statistically significant reduction in PV energies productivity of up to $7 \%$ is observed in Eastern Europe and northern Africa, while a significant increase of up to $10 \%$ is observed in Western Europe and the eastern Mediterranean.

All the studies cited above show a diversity of trends, both on a continental scale and in some countries, and this reflects the need to continue to carry out similar studies both at sub-regional level and at lower scales. This explains why the present study is oriented towards West-Africa.

The study area, used data and the methodological approach are described in the next section 2. Section 3 is only reserved to the results. The section 4 presents the concluding remarks and proposed some recommendations for future improvements in this kind of analysis.

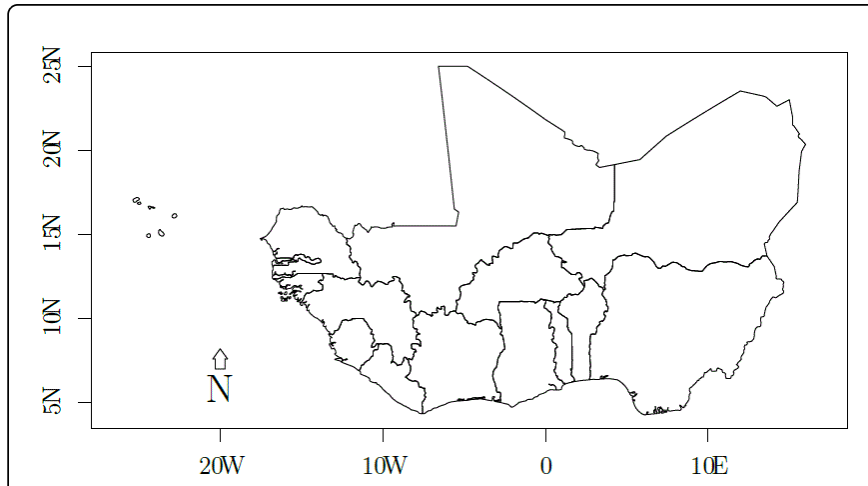

Figure 1: Region of interest: Economic community of West African States (ECOWAS) constituted of 15 states.

\section{Data and Methodology}

\section{Study area}

The Figure 1 presents the study area. The first reason which led to study this region is found at ECREEE [5]. Indeed less than half of the 334.6 million ECOWAS citizens have access to electricity services today. The projections show that by 2050, Nigeria will become the third most populous country in the world With an average regional population growth rate of $2.5 \%$ and regional economic growth generally projected to accelerate, rising demand for energy and other resources will continue to pose a major challenge in the decades ahead, contributing to the urgent need to improve energy efficiency and deploy renewable energy solutions. Another reason is that the region is one of the sunniest areas of the world. Solar radiation reaching the earth resource to meet the rapidly growing energy demands of the world on a renewable carbon and nuclear-free basis Wild et al. [18]. Direct use of this resource through (PV) energy conversion has become the major contributor to this trend in recent years, reaching an installed capacity of more than $150 \mathrm{GW}$ in 2014 [19].

\begin{tabular}{|l|l|l|}
\hline Institute ID & Global Model Name & Model Short Name \\
\hline NOAA-GFDL & GFDL-ESM2M & NOAA \\
\hline NCC & NorESM1-M & NCC \\
\hline MPI-M & MPI-ESM-LR & MPI \\
\hline MIROC & MIROC5 & MIROC \\
\hline IPSL & IPSL-CM5A-MR & IPSL \\
\hline ICHEC & EC-EARTH & ICHEC \\
\hline CNRM-CERFACS & CNRM-CM5 & CNRM \\
\hline CCCMa & CanESM2 & CCCMA \\
\hline
\end{tabular}

Table 1: Used climatic models. Institute of origin (Column 1), global model under which they are run (Column 2) and the short name of regional climate model (Column 3).

A final reason is that the life of the great rural mass population of this area is threatened because heavily dependent on rained agriculture 
Citation: Bazyomo SD, Lawin EA, Ouedraogo A (2017) Seasonal Trends in Solar Radiation Available at the Earth's Surface and Implication of Future Annual Power Outputs Changes on the Photovoltaic Systems with One and Two Tracking Axes. J Climatol Weather Forecasting 5: 201. doi:10.4172/2332-2594.1000201

Page 3 of 9

which is degraded by climatic changes. Such results could help to anticipate the future impacts of climate changes on vegetation's.

\section{Data sources}

The Table 1 presents the data used in this study. It is a set of eight climatic models outputs with daily time step and spatial resolution of $0.44^{\circ}$ and available at: https://esgf-data.dkrz.de/projects/esgf-dkrz/. Climatic models are complex programs based on atmospheric circulation including its chemistry and radiation, oceanic circulation including its biochemistry, land-surface, river routing and sea ice modeling. The differences between them are mainly related to the physical parameterization of each component of the model structure. The components of the model are based on the scenario or Representative Concentration Pathway (RCP). Within Coupled Model Inter comparison Project Phase 5 (CMIP5), predefined scenarios of radioactive forcing obtained from socio-economic scenarios were used for the projections of climate change [20,21].

On the technical aspects, the data set is the latest of climatic models outputs and they are run under the scenario A2r. This scenario combines assumptions about high population and relatively slow income growth with modest rates of technological change and energy intensity improvements, leading in the long term to high energy demand and greenhouse gases emissions [22]. Details of land use categories such as cultivated land, built up land and forests and grassland area can be found at Schmidhuber and Tubiello [23]. Comparatively to the others scenarios this one represents the highest greenhouse emission. It implies a Representative Concentration Pathway of $8.5 \mathrm{~W} / \mathrm{m}^{2}$ and projects on average a global warming of $2^{\circ} \mathrm{C}$ and $3.7^{\circ} \mathrm{C}$ until the mid and late 21 st century respectively relative to a reference period 1985-2005 [23,24]. Finally, the climate of West Africa poses particular problems for climate models among which the unavailability of observations which are used as boundary conditions to correct the forecast data during the simulation. So, many variables like temperature and radiation are purely model products. Furthermore Ayompe and Duffy [25] counted twenty two radiometers sites across the West Africa. So, it is very important to present this kind of study which gives trends of future solar radiation and applications.

\section{The used methods}

All the files are on the format Network Common Data (NetCDF). The seasonal averages as well as that annual were calculated using the Climate Data Commands (CDO 2015: Available at: http:// www.mpimet.mpg.de/cdo). Then, the free software $\mathrm{R}$ [26] is used to compute all the statistical parameters such as the slopes, minimum and maximum and all the plots presented in the following.

The performance of PV modules is maximum when the sun light reaches $90^{\circ}$ angle with its surface [27] and depends on azimuth and solar altitude angles. One and two axes PV system is designed to meet this condition. To compute the yearly sum of irradiation which reaches the surface of thesis two of types tracking, the free package solar [28] is used. More details and examples on this method can be found at Antonanzas et al. [29].

The equation $1[18,30]$ allowed to assess the influence of temperature on tracking systems performance.

$$
\begin{aligned}
\frac{{ }^{\Delta P} p v}{P_{p v}} & =-\Delta T G_{t o t} \beta C_{2}-\Delta G_{t o t}^{2} \beta C_{3} \\
& +G_{t o t}\left(1-\beta C_{1}+\beta t_{r e f}-2 \beta C_{3}-T \beta C_{2}\right)+\Delta G_{t o t} \Delta T \beta C_{2} \\
& +G_{t o t} \gamma \log _{10}\left(G_{t o t}+\Delta G_{t o t}\right)+G_{t o t} \gamma \log _{10}\left(\frac{G_{t o t}+G_{t o t}}{G_{t o t}}\right)
\end{aligned}
$$

Where $\mathrm{T}$ the air ambient temperature in ${ }^{\circ} \mathrm{C}, \mathrm{C}_{1}, \mathrm{C}_{2}$ and $\mathrm{C}_{3}$ depend of the material properties and in this case (mono-crystalline silicon cells) their values are $C_{1}=-3.75, C_{2}=1.14$ and $C_{3}=0.0175 \mathrm{~m}^{2} \mathrm{~W}^{-1}$, $\beta=0.0045$ and $\gamma=0.1$ and $G_{\text {tot }}$ is the total irradiation which reaches the system surface.

\section{Results}

\section{Inter annual trends in seasonal solar radiation}

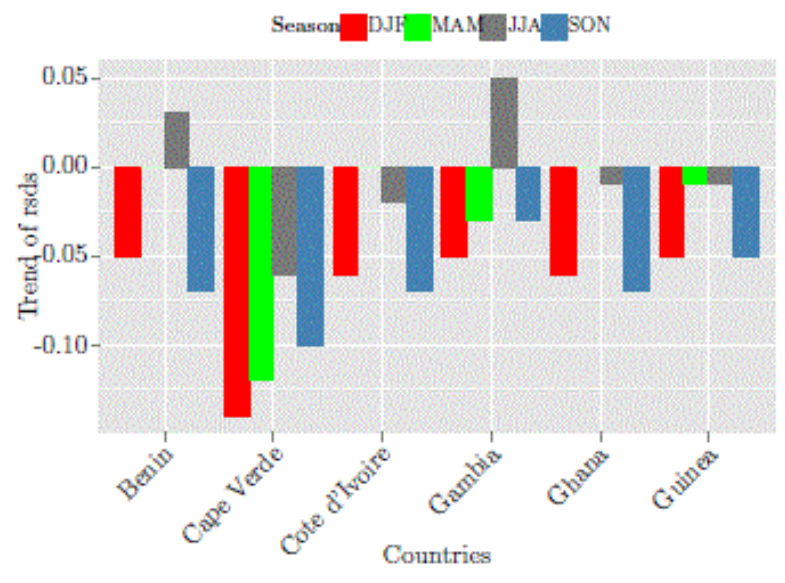

(a) Inter-annual trends in seasonal solar radiation

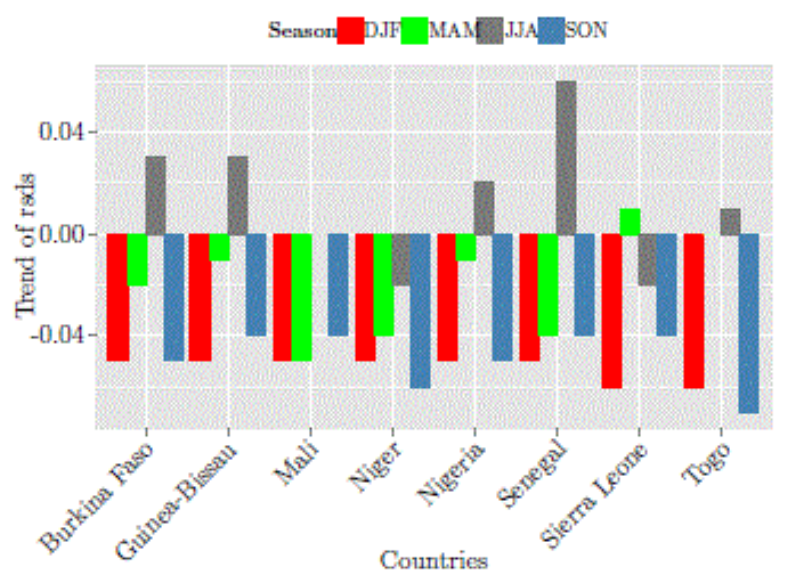

(b) Inter-annual trends in seasonal solar radiation (Suite)

Figure 2: Bar plots of trend (W.m ${ }^{-2}$ year $^{-1}$ ) of each season solar radiation between 2006-2100. The group of 3 bars means that one season trend is zero. 
Citation: Bazyomo SD, Lawin EA, Ouedraogo A (2017) Seasonal Trends in Solar Radiation Available at the Earth's Surface and Implication of Future Annual Power Outputs Changes on the Photovoltaic Systems with One and Two Tracking Axes. J Climatol Weather Forecasting 5: 201. doi:10.4172/2332-2594.1000201

Page 4 of 9

The calculation of the trend in rsds was done into two parts. The first part is based over the period 2006-2100. The Figure 2 presents the results of the trends for each season and by country. The examination of this figure shows that the trends are null or negative accepted of the trends of period JJA for the countries like Burkina Faso, GuineaBissau, Nigeria, Senegal, Togo, Benin and Gambia. For the positive trends, the maximum is $0.05 \mathrm{~W} . \mathrm{m}^{-2}$ year-1 for Gambia.

Concerning the null trends, no change is planned for season JJA in Mali and season MAM in Togo, Benin, Cote d'Ivoire and Ghana. For the negative changes, strongest is $0.15 \mathrm{~W} . \mathrm{m} 2$ year- 1 and corresponds to the season DJF for the Cape Verde. In a general way, the trends of season MAM are weakest of negative trends accepted the case of Niger, Sierra Leone and the Cape Verde where it is season JJA. Guinea and Gambia present trends which are equal for respectively the periods MAM, SON and MAM, JJA.
The second part consists in determining the trends of the seasons between the near future 2006-2050 and far future 2051-2100. This decomposition makes possible to notice more characteristics which can be masked by the long size of the series 2006-2100. The results of periods 2006-2050 are present in the Table 2.

Compared to the periods 2006-2100, all the trends are more marked. These trends also evolve between positive and negative values. The strongest negative trend is of $0.36 \mathrm{~W} . \mathrm{m}^{-2}$ year ${ }^{-1}$ for the period SON and the Cape Verde. The maximum ones of the trends for period JJA are all positive except the Cape Verde which presents a downward trend of $-0.05 \mathrm{~W} \cdot \mathrm{m}^{-2}$ year $^{-1}$.

\begin{tabular}{|c|c|c|c|c|c|c|c|c|}
\hline \multirow[b]{2}{*}{ Country } & \multicolumn{2}{|l|}{ DJF $^{1}$} & \multicolumn{2}{|l|}{ MAM $^{2}$} & \multicolumn{2}{|l|}{ JJA $^{3}$} & \multicolumn{2}{|l|}{ SON $^{4}$} \\
\hline & $\min$ & $\max$ & $\min$ & $\max$ & $\min$ & $\max$ & $\min$ & $\max$ \\
\hline Benin & -0.17 & -0.06 & -0.24 & -0.02 & -0.3 & 0.01 & -0.24 & -0.04 \\
\hline Cape Verde & -0.25 & -0.1 & -0.19 & -0.09 & -0.26 & -0.05 & -0.36 & -0.08 \\
\hline Gambia & -0.09 & -0.06 & -0.11 & -0.03 & -0.12 & 0.02 & -0.16 & -0.04 \\
\hline Ghana & -0.23 & -0.07 & -0.21 & -0.02 & -0.29 & 0.03 & -0.21 & -0.04 \\
\hline Guinea & -0.11 & -0.04 & -0.23 & -0.03 & -0.25 & 0.01 & -0.2 & -0.06 \\
\hline Cote d'Ivoire & -0.2 & -0.07 & -0.24 & -0.02 & -0.22 & 0.04 & -0.21 & -0.04 \\
\hline Liberia & -0.22 & -0.06 & -0.21 & -0.03 & -0.16 & 0.03 & -0.2 & -0.03 \\
\hline Mali & -0.1 & -0.05 & -0.16 & -0.06 & -0.14 & 0.03 & -0.13 & 0 \\
\hline Niger & -0.08 & -0.05 & -0.13 & -0.05 & -0.18 & 0.01 & -0.09 & 0.01 \\
\hline Nigeria & -0.11 & -0.05 & -0.22 & -0.03 & -0.23 & 0 & -0.16 & -0.03 \\
\hline Guinea-Bissau & -0.09 & -0.05 & -0.19 & -0.04 & -0.18 & 0.02 & -0.16 & -0.07 \\
\hline Senegal & -0.09 & -0.06 & -0.1 & -0.03 & -0.09 & 0.03 & -0.16 & -0.04 \\
\hline Sierra Leone & -0.14 & -0.04 & -0.25 & -0.04 & -0.19 & 0.02 & -0.2 & -0.05 \\
\hline Togo & -0.21 & -0.07 & -0.23 & -0.03 & -0.32 & 0.01 & -0.22 & -0.05 \\
\hline Burkina Faso & -0.11 & -0.06 & -0.2 & -0.03 & -0.25 & 0.01 & -0.17 & 0 \\
\hline $\begin{array}{l}\text { 1DJF: December January February } \\
\text { 2MAM: March April May } \\
\text { 3JJA: June July August } \\
{ }^{4} \mathrm{SON}: \text { September October November }\end{array}$ & & & & & & & & \\
\hline
\end{tabular}

Table 2: Minimum and maximum of trend $\left(\mathrm{W} \cdot \mathrm{m}^{-2}\right.$ year $\left.{ }^{-1}\right)$ per Country and for each season between 2006-2050.

Compared to the period 2006-2051, the results of the trends seasonal of 2051-2100 present at the Table 3 are marked for certain countries and less for others. The common point is that the Cape Verde always presents the trends weakest of $0.55 \mathrm{~W} \cdot \mathrm{m}^{-2}$ year $^{-1}$ for the minimum of season JJA. The maximum ones as of period JJA which was all positive except for case of the Cape Verde are positive for the countries like Benin, Gambia, Nigeria, Senegal and Togo and worthless for Burkina Faso and Guinea-Bissau.

The weakest trends were left again between the minimal ones of seasons JJA and SON (Figure 3). 
Citation: Bazyomo SD, Lawin EA, Ouedraogo A (2017) Seasonal Trends in Solar Radiation Available at the Earth's Surface and Implication of Future Annual Power Outputs Changes on the Photovoltaic Systems with One and Two Tracking Axes. J Climatol Weather Forecasting 5: 201. doi:10.4172/2332-2594.1000201

Page 5 of 9

\begin{tabular}{|c|c|c|c|c|c|c|c|c|}
\hline \multirow[b]{2}{*}{ Country } & \multicolumn{2}{|l|}{ DJF$^{1}$} & \multicolumn{2}{|c|}{ MAM $^{2}$} & \multicolumn{2}{|l|}{$J_{J A}{ }^{3}$} & \multicolumn{2}{|l|}{ SON $^{4}$} \\
\hline & $\min$ & $\max$ & $\min$ & $\max$ & $\min$ & $\max$ & $\min$ & $\max$ \\
\hline Benin & -0.13 & -0.05 & -0.14 & 0.02 & -0.23 & 0.05 & -0.33 & -0.08 \\
\hline Cape Verde & -0.44 & -0.14 & -0.4 & -0.16 & -0.55 & -0.04 & -0.39 & -0.12 \\
\hline Gambia & -0.12 & -0.06 & -0.13 & -0.05 & -0.18 & 0.05 & -0.25 & -0.05 \\
\hline Ghana & -0.18 & -0.06 & -0.13 & 0.03 & -0.28 & -0.02 & -0.31 & -0.07 \\
\hline Guinea & -0.14 & -0.06 & -0.15 & -0.01 & -0.28 & -0.04 & -0.27 & -0.05 \\
\hline Cote d'Ivoire & -0.19 & -0.07 & -0.11 & 0.02 & -0.27 & -0.03 & -0.29 & -0.06 \\
\hline Liberia & -0.19 & -0.06 & -0.08 & 0.02 & -0.28 & -0.06 & -0.25 & -0.05 \\
\hline Mali & -0.08 & -0.05 & -0.17 & -0.05 & -0.34 & -0.04 & -0.17 & -0.06 \\
\hline Niger & -0.08 & -0.05 & -0.19 & -0.05 & -0.33 & -0.05 & -0.18 & -0.08 \\
\hline Nigeria & -0.12 & -0.04 & -0.13 & 0.01 & -0.27 & 0.03 & -0.24 & -0.04 \\
\hline Guinea-Bissau & -0.12 & -0.06 & -0.13 & -0.02 & -0.23 & 0 & -0.24 & -0.05 \\
\hline Senegal & -0.11 & -0.06 & -0.15 & -0.05 & -0.2 & 0.06 & -0.23 & -0.06 \\
\hline Sierra Leone & -0.23 & -0.07 & -0.11 & 0.02 & -0.32 & -0.06 & -0.32 & -0.05 \\
\hline Togo & -0.17 & -0.05 & -0.14 & 0.02 & -0.26 & 0.02 & -0.32 & -0.08 \\
\hline Burkina Faso & -0.1 & -0.05 & -0.19 & -0.02 & -0.33 & 0 & -0.27 & -0.05 \\
\hline $\begin{array}{l}\text { 1DJF: December January February } \\
\text { 2MAM: March April May } \\
\text { 3JJA: June July August } \\
{ }^{4} \mathrm{SON}: \text { September October November }\end{array}$ & & & & & & & & \\
\hline
\end{tabular}

Table 3: Minimum and maximum of trend (W. $\mathrm{m}^{-2}$ year $\left.^{-1}\right)$ per country and for each season between 2051-2100.

\section{Case of June-July-August-September (JJAS) period}

The Figure 4 presents spatial of the trend between 2006-2100 of the solar irradiation for season JJAS.

The interest to study this period (JJAS) is that during this period falls almost all the rains of the region [31], and the population primarily rural are very vulnerable because of their strong dependence on rain agriculture. So this study complete the one of whose deal with the projected precipitation for the same period and region [32]. Considering the Figure $3 \mathrm{~b}$, the median trends strongest seem made up a horizontal band which goes from Senegal, passing by Mali, north of Burkina Faso, the south of Niger to go down over all the Nigeria. This same band is noticed on the level of the Figure $3 \mathrm{c}$ which presents the greatest values of the trend.

However on the level of the Figure $3 \mathrm{c}$ the band is more horizontal. The countries in the south of the area share the same cases of the downward trends.

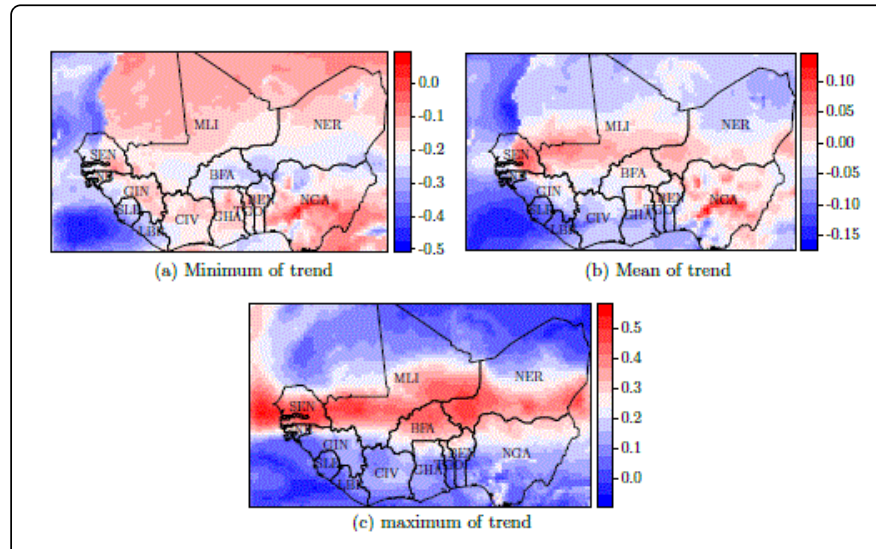

Figure 3: Plots of June-July-August-September mean period trend between 2006-2100 with $3 \mathrm{a}$ the minimum, $3 \mathrm{~b}$ the mean and $3 \mathrm{c}$ the maximum. Legend shows changes in W. $\mathrm{m}^{-2}$ year $^{-1}$. 
Citation: Bazyomo SD, Lawin EA, Ouedraogo A (2017) Seasonal Trends in Solar Radiation Available at the Earth's Surface and Implication of Future Annual Power Outputs Changes on the Photovoltaic Systems with One and Two Tracking Axes. J Climatol Weather Forecasting 5: 201. doi:10.4172/2332-2594.1000201

Page 6 of 9

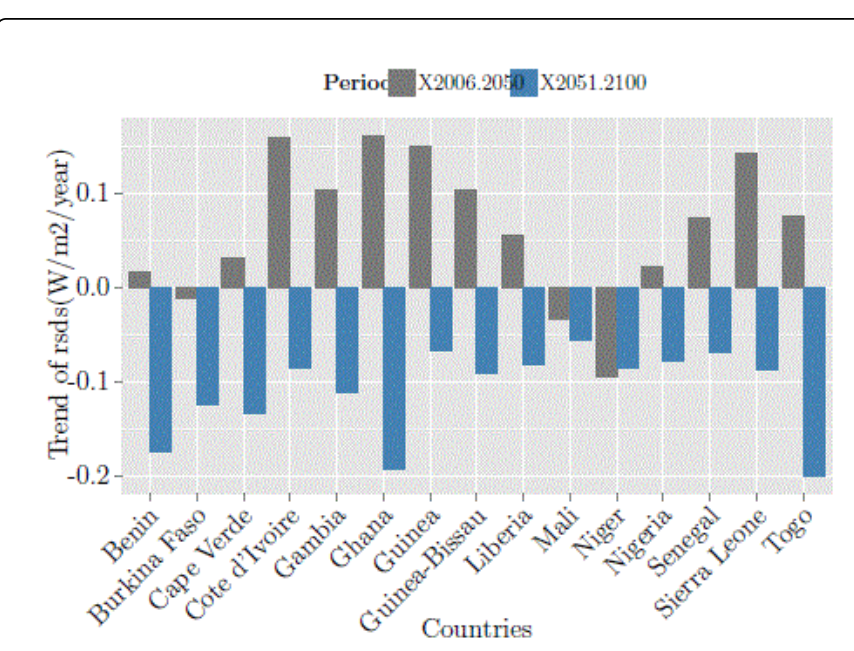

Figure 4: Comparison of annual trend for each country for the period 2006-2050 and 2051-2100.

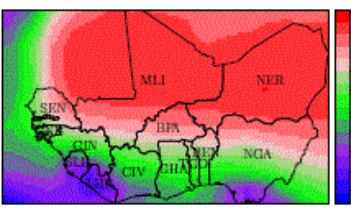

(a) Minimum values of irradiation

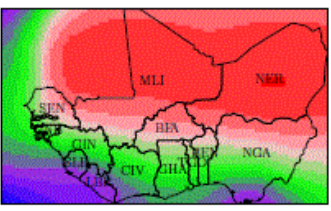

(c) Mean values of irradiation

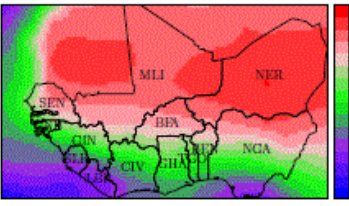

(e) Maximum values of irradiation

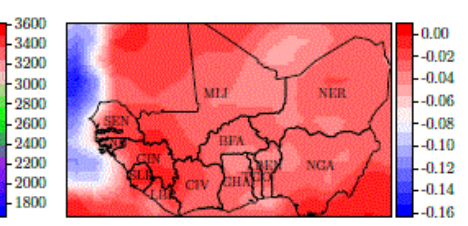

(b) Minimum values of trend

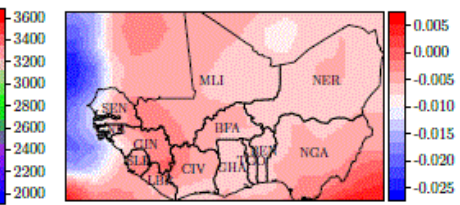

(d) Mean values of trend

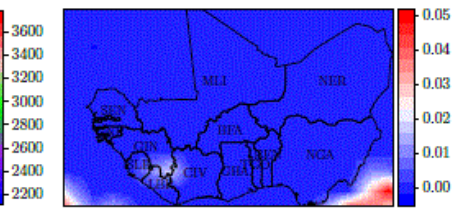

(f) Maximum values of trend
Figure 5: Global map of solar irradiation repartition minimum (5a), mean $(5 \mathrm{c})$ and maximum (5e) and trend repartition (\%.year $\left.{ }^{-1}\right)$. Minimum (5b), mean (5d), maximum (5f).

\section{Impact of climate changes on one and two PV tracking}

The results of this section are based on the changes of power outputs without the influences of others factors like temperature, wind and rain. The fractional changes $\Delta \mathrm{P} / \mathrm{P}$ is calculated for both $\mathrm{PV}$ system with one axis rotation Figure 5 and two rotation axes 6 .

Figures $5 \mathrm{~b}, 5 \mathrm{~d}$ and $5 \mathrm{f}$ present respectively the minimum, mean and maximum of percentage changes in PV with one axis rotation from 2006 to 2045 relatively to the period 2006-2015. PV output is likely to decrease for the whole region. Higher latitudes which present higher values of solar irradiation $(5 \mathrm{a}, 5 \mathrm{c}, 5 \mathrm{e})$ do not present the same trends on the percentage changes. Like Figures 5 and 6 shows the results concerning the PV system with two rotation axes. Compare with one rotation axis, no significant differences are observed between percentage changes in power outputs of these two types of PV technologies. These situations is more accurate in the results presented in the Table 4 which shows the statistics by country does not allowed to make an absolute comparison on the future behaviors of these two technologies.

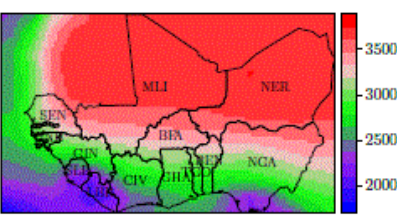

(a) Minimum values of irradiation

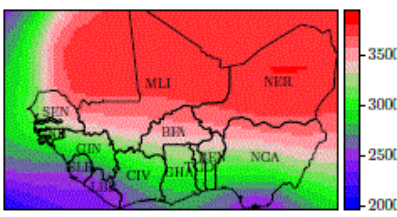

(c) Mean of irradiation

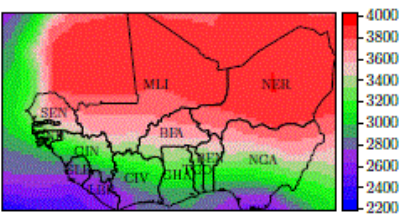

(e) Maximum values of irradiation

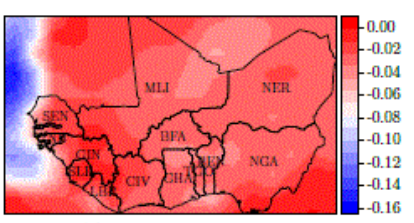

(b) Minimum values of trend

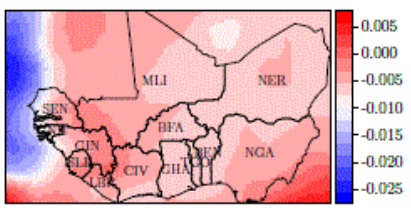

(d) Mean of trend

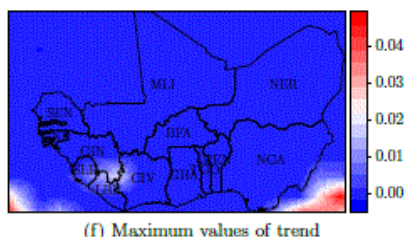

(f) Maximum values of trend
Figure 6: Like Figure 3, this figure presents global map of solar irradiation repartition minimum (6a), mean (6c) and maximum (6e) and trend repartition (\%.year $\left.{ }^{-1}\right)$ minimum (6b), mean (6d), maximum (6f).

\begin{tabular}{|l|l|l|l|l|l|l|}
\hline \multirow{2}{*}{ Country } & \multicolumn{3}{l}{ Minimal } & Mean & \multicolumn{2}{l|}{ Maximal } \\
\cline { 2 - 8 } & Hori.1 & Two 2 & Hori.1 & Two 1 & Hori.1 & Two 1 \\
\hline Benin & -0.04 & -0.05 & -0.01 & -0.01 & 0 & 0 \\
\hline Ghana & -0.05 & -0.05 & -0.01 & -0.01 & 0 & 0 \\
\hline Guinea & -0.06 & -0.06 & 0 & 0 & 0.02 & 0.02 \\
\hline Cote d'Ivoire & -0.03 & -0.03 & 0 & 0 & 0.02 & 0.02 \\
\hline
\end{tabular}


Citation: Bazyomo SD, Lawin EA, Ouedraogo A (2017) Seasonal Trends in Solar Radiation Available at the Earth's Surface and Implication of Future Annual Power Outputs Changes on the Photovoltaic Systems with One and Two Tracking Axes. J Climatol Weather Forecasting 5: 201. doi:10.4172/2332-2594.1000201

Page 7 of 9

\begin{tabular}{|l|l|l|l|l|l|l|}
\hline Liberia & -0.04 & -0.04 & 0 & 0 & 0.01 & 0.01 \\
\hline Mali & -0.04 & -0.04 & 0 & 0 & 0 \\
\hline Niger & -0.04 & -0.03 & -0.01 & 0 & 0 \\
\hline Nigeria & -0.04 & -0.04 & 0 & 0 & 0 & 0 \\
\hline Guinea-Bissau & -0.07 & -0.07 & -0.01 & 0 & 0 & 0 \\
\hline Senegal & -0.08 & -0.08 & -0.01 & 0 & 0 & 0 \\
\hline Sierra Leone & -0.03 & -0.02 & 0 & 0 & 0.01 \\
\hline Togo & -0.04 & -0.04 & -0.01 & -0.01 & 0 \\
\hline Burkina Faso & -0.04 & -0.04 & -0.01 & 0 & 0 \\
\hline $\begin{array}{l}\text { 1Horizontal axis rotation PV system } \\
\text { 2Two axis rotation PV system }\end{array}$ & & & 0 \\
\hline
\end{tabular}

Table 4: Minimum and maximum of trend $\left(\%\right.$ year $\left.^{-1}\right)$ between 2006-2045 per country considering the two types of PV technologies.

\section{Influence of temperature}

On opposite to the previous section (3.3) the results presented in this one take in count the impact of temperature using the equation 1.

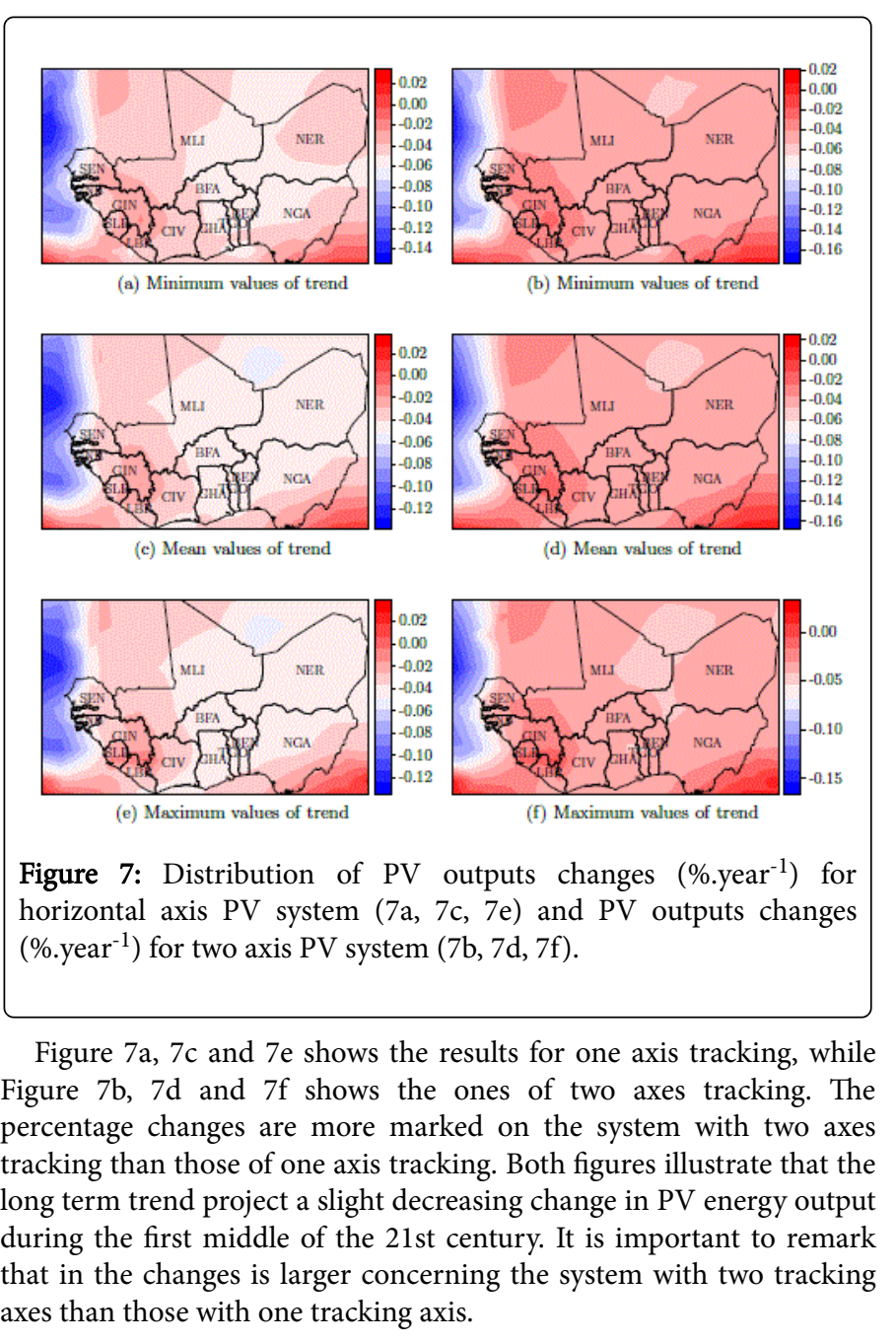

The median values indicate a slight variation of the output power which is about $-1 \% /$ decade for the countries like Benin, Ghana, Guinea-Bissau, Togo and Burkina Faso. The largest decreases trends strongest go from $-3 \%$ respectively to $-8 \% /$ decade for the systems with axes of traction for the Sierra Leone and the Co^te d'Ivoire respectively and from -2 to $-8 \% /$ decade for the systems with two axes of tractions for the Sierra Leone and the Co^te d'Ivoire. In way general the trends vary between 3 and 5\%/decade except the case of Senegal where values reach up to $8 \% /$ decade.

\section{Discussion and Conclusion}

This paper objective are to study the seasonal variations of the rsds on the one hand and to determine the future annual changes of the outputs powers for motorized systems (one and two axes of rotation). West Africa is the region of interest and data are the latest projections of climate change (RCP 8.5).

The seasonal changes shown in Figure 2 and Table 2 indicate a decreasing trend for all seasons and for the entire region. The seasonal results have the same trends as those found by Dimitri et al. [33] but that concerned the annual trends. To have better comprehension of results of in this paper it is important to look at the results of other regions for the same dataset. Wild et al. [18] found increasing trends in annual rsds for western and Eastern Europe, southwestern China. The reason for this situation can be found in the fact that most part of the countries in this part of the world has adopted major's policies in electricity, transport, cooling and hotting which involve the use of renewable energies. Which in the long term reduce the emissions of greenhouse gases? Meanwhile, although policies are oriented towards renewable energies with the creation of supra-national institutions like the Ecowas Center for Renewable Energy Efficiency (ECREE) and often ministries devoted to renewable energies, practical actions are slow to come.

Another analysis but which does not return within the framework of this study could concern impacts of decreasing reduction in the rsds on the environment in particular the plants in term of photosynthesis.

Although motorized PV systems offer higher efficiencies than fixed PV systems, the results presented in Figure 7 show decreasing trends 
Citation: Bazyomo SD, Lawin EA, Ouedraogo A (2017) Seasonal Trends in Solar Radiation Available at the Earth's Surface and Implication of Future Annual Power Outputs Changes on the Photovoltaic Systems with One and Two Tracking Axes. J Climatol Weather Forecasting 5: 201. doi:10.4172/2332-2594.1000201

Page 8 of 9

higher than fixed PV systems. These results are in agreement with those of Wild et al. [18] Faced with a population that is expected to increase by more than $150 \%$ by 2050 [34], the development of other sources of renewable energies could fill the shortfall.

Forecasting the AC power output of a PV plant accurately is important both for plant owners and electric system operators [35]. More in this tendency of renewable energies which depend on the climate variables, more details on the future behaviors of PV plants are important. In this paper, the seasonal trends of solar resources and the changes of power output using the one and two tracking axes have been explored. The results show that for trends from 2006-2100 the maximum is of $0.05 \mathrm{~W} . \mathrm{m}^{-2}$ year ${ }^{-1}$ for Gambia and over the period JJA while the changes strongest negative change $0.15 \mathrm{~W} \cdot \mathrm{m}^{-2}$ year ${ }^{-1}$ and corresponds has season DJF with the Cape Verde. Compared with the periods 2006-2100, all the trends the period 2006-2050 and 20512100 are more marked. Compared to the period 2006-2051, the results of the trends seasonal of the period 2051-2100 are marked for certain countries and less for others. Cape Verde always presents the trends weakest of $0.55 \mathrm{~W} . \mathrm{m}^{-2}$ year $^{-1}$ for the minimum of season JJA. Concerning future changes of power output, largest decreases trends strongest go from $-3 \%$ respectively to $-8 \% /$ decade for the systems with axis of traction for the Sierra Leone and the Co^te d'Ivoire respectively and from -2 to $-8 \%$ /decade for the systems with two axes of tractions for the Sierra Leone and the Cote d'Ivoire

The northern part of this study area is well known to be marked by the harmattan, a dry wind blowing from the Sahara on the West Africa and cause a serious deposit of dust on the PV panel surfaces. In Further study we the effects of the dust on PV systems efficiencies could be explored. More like mentioned at the end of the section 2.2 many climate data are purely model products. This situation prevents a rigorous description of solar irradiation compare with on ground data. Moreover these data are still highly uncertain with respect to the future evolution of greenhouse gas emissions, greenhouse gas concentrations in the atmosphere and GCC [36]. So a further line of reflection could first be focused on the comparison between the modelled data and on ground data by using the CM-SAF data [37] and a second study be focused on the comparison of the different influences of the other RCP on the outputs of PV systems.

\section{Acknowledgments}

The authors gratefully acknowledge the German Academic Exchange Service (DAAD) for financially supporting this research work.

\section{References}

1. Pereira MG, Camacho CF, Aurelio M, Freitas V, Fidelis N (2012) The renewable energy market in Brazil: Current status and potential. Renew Sust Energ Rev 16: 3786-3802.

2. Pereira AO, Soares JB, de Oliveira RG, de Queiroz RP (2008) Energy in Brazil: Toward sustainable development? Energ Policy 36: 73-83.

3. Chu Y (2011) Review and Comparison of Different Solar Energy Technologies.

4. International Energy Agency (IEA) (2006) Key World Energy Statistics 2006, Paris, France.

5. Centre for Renewable Energy and Energy Efficiency (ECREEE) (2012) Baseline Report for the ECOWAS Renewable Energ Policy (EREP).

6. Parida B, Iniyan S, Goic R (2011) A review of solar photovoltaic technologies.
7. Sungur C (2009) Multi-axes sun-tracking system with PLC control for photovoltaic panels in Turkey. Renew Energ 34: 1119-1125.

8. Yao Y, Hu Y, Gao S, Yang G, Du J (2014) A multipurpose dual-axis solar tracker with two tracking strategies, Renew Energ 72: 88-98.

9. Eke R, Senturk A (2012) Performance comparison of a double-axis sun tracking versus fixed PV system. Sol Energ 86: 2665-2672.

10. Dhanabal R, Bharathi V, Ranjitha R, Ponni A, Deepthi S, et al. (2013) Comparison of efficiencies of solar tracker systems with static panel single-axis tracking system and dual-axis tracking system with fixed mount. Int J Eng Technol 5: 1925-1933.

11. COSTA (2015) Optimization Approach to the Design and Trajectory Planning of Sun Tracking Photovoltaic Power Plants, Ph.D. thesis, Technical University of Lisbon.

12. Gaetani M, Huld T, Vignati E, Monforti-Ferrario F, Dosio A, et al. (2014) The near future availability of photovoltaic energy in Europe and Africa in climate-aerosol modeling experiments.

13. Muller K, Wild B, Driesse M, Behrens A (2014) Rethinking solar resource assessments in the context of global dimming and brightening. Sol Energ 99: 272-282.

14. Zell E, Gasim S, Wilcox S, Katamoura S, Stoffel T, et al. (2015) Assessment of solar radiation resources in Saudi Arabia. Sol Energ 119: 422-438.

15. Cedric B, Adam Schlosser C (2014) Characterization of the Solar Power Resource in Europe and Assessing Benefits of Co-Location with Wind Power Installations. Tech Rep Report.

16. Stanton MCB, Dessai S, Paavola J (2016) A systematic review of the impacts of climate variability and change on electricity systems in Europe. Energy 109: 1148-1159.

17. Crook JA, Jones LA, Forster PM, Crook R (2011) Climate change impacts on future photovoltaic and concentrated solar power energy output. Energ Environ Sci 4: 3101.

18. Wild M, Folini D, Henschel F, Fischer N, Muller B (2015) Projections of long-term changes in solar radiation based on CMIP5 climate models and their influence on energy yields of photovoltaic systems. Sol Energ 116: 12-24.

19. European Photovoltaic Industry Association (EPIA) (2014) Global Market Outlook for Photovoltaics 2014-2018. Brussels.

20. Moss R, Edmonds J, Hibbard K, Manning M, Rose S, et al. (2010) The next generation of scenarios for climate change research and assessment. Nature 463: 747-756.

21. Van Vuuren DP, Edmonds J, Kainuma M, Riahi K, Thomson A, et al. (2011) The representative concentration pathways: An overview. Clim Change 109: 5-31.

22. Riahi K, Rao S, Krey V, Cho C, Chirkov V, et al. (2011) RCP 8.5 A scenario of comparatively high greenhouse gas emissions.

23. Schmidhuber J, Tubiello FN (2007) Global food security under climate change. Proc Natl Acad Sci 104: 19703-19708.

24. IPCC Climate Change (2013) The Physical Science Basis. Contribution of Working Group I to the Fifth Assessment Report of the Intergovernmental Panel on Climate Change. Intergovernmental Panel on Climate Change 1535.

25. Ayompe L, Duffy A (2014) An assessment of the energy generation potential of photovoltaic systems in Cameroon using satellite derived solar radiation datasets. Sustainable Energy Technologies and Assessments 7: 257-264.

26. R Development Core (2008) R, R: A language and environment for statistical computing. R Foundation for Statistical Computing, Vienna, Austria.

27. Khadidja B, Dris K, Boubeker A, Noureddine S (2014) Optimisation of a solar tracker system for photovoltaic power plants in Saharian region, example of Ouargla. in: Energy Procedia 50: 610-618.

28. Perpinan O, sola R (2012) Solar Radiation and Photovoltaic Systems Perpin. Statistical Software 50: 132.

29. Antonanzas-Torres F, Canizares F, Perpinan O (2013) Comparative assessment of global irradiation from a satellite estimate model (CM SAF) 
Citation: Bazyomo SD, Lawin EA, Ouedraogo A (2017) Seasonal Trends in Solar Radiation Available at the Earth's Surface and Implication of Future Annual Power Outputs Changes on the Photovoltaic Systems with One and Two Tracking Axes. J Climatol Weather Forecasting 5: 201. doi:10.4172/2332-2594.1000201

Page 9 of 9

and on-ground measurements (SIAR): A Spanish case study. Renew Sustain Energ Rev 21: 248-261.

30. Panagea S, Tsanis IK, Koutroulis AG, Grillakis MG (2014) Climate change impact on photovoltaic energy output: The case of Greece. Advances in Meteorology.

31. Korgo B (2014) Caracterisation optique et microphysique des aerosols atmospheriques en zone urbaine ouest africaine: application aux calculs $\mathrm{du}$ for, cage radiatifa Ouagadougou, Ph.D. thesis, Universite Blaise Pascal Clermont Ferrand I.

32. Klutse NAB, Sylla MB, Diallo I, Sarr A, Dosio A (2016) Daily characteristics of West African summer monsoon precipitation in CORDEX simulations. Theoret Appl Climatol 123: 369-386.
33. Dimitri S, Buri Y, Coulibaly O, Ouedraogo A (2016) Forecasted Changes in West Africa Photovoltaic Energy Output by 2045. Climate 4: 1-15.

34. Eurogroup Consulting (2015) Lenergie en Afrique a lhorizon 2050.

35. Almeida MP, Perpinan O, Narvarte L (2015) power forecast using a nonparametric PV model. Sol Energ 115: 354-368.

36. Szklo DA, Schaeffer R, Desouza R, Borba B, Dacosta I, et al. (2008) The vulnerability of renewable energy to climate change in Brazil. Energ Policy 37: 879-889.

37. Muller R, Richard K (2015) Surface Solar Radiation Data Set. Satellite Application Facility on Climate Monitoring. 